\title{
Are fluctuations in personality states more than just fluctuations in affect?
}

\author{
Robert E. Wilson, ${ }^{\mathrm{a}, *}$ Renee J. Thompson, ${ }^{\mathrm{b}}$ Simine Vazire ${ }^{\mathrm{a}}$ \\ a University of California, Davis, United States \\ ${ }^{\mathrm{b}}$ Washington University in St. Louis, United States
}

\section{A R T I C L E IN F O}

Article history:

Received 3 October 2015

Received in revised form 11 May 2016

Accepted 4 June 2016

Available online $\mathrm{xxx}$

Keywords:

Personality states

Affect

Situations' $\mathrm{P} \times \mathrm{S}$ interactions

\section{A B S T R A C T}

People fluctuate in their behavior as they go about their daily lives, but little is known about the processes underlying these fluctuations. In two ecological momentary assessment studies $(\mathrm{Ns}=124,415)$, we examined the extent to which negative and positive affect accounted for the within-person variance in Big Five states. Participants were prompted six times a day over six days (Study 1) or four times a day over two weeks (Study 2) to report their recent thoughts, feelings, and behaviors. Multilevel modeling results indicated that negative and positive affect account for most, but not all, of the within-person variance in personality states. Importantly, situation variables predicted variance in some personality states even after accounting for fluctuations in affect, indicating that fluctuations in personality states may be more than fluctuations in state affect.

(C) 2016 Published by Elsevier Ltd.

\section{Introduction}

Empirical evidence has confirmed that people fluctuate extensively in their behavior as they go about their daily lives (Fleeson, 2001; Heller, Komar, \& Lee, 2007). Understanding why people fluctuate from one situation to another and how people differ in their patterns of fluctuations is central to understanding the very essence of personality beyond personality traits (Allport, 1937; Lewin, 1936; Magnusson \& Endler, 1977; Mischel \& Shoda, 1995). Conceptually, it is useful to think of fluctuations in behavior over time and across situations as a density distribution of states, or a temporary way of being, that centers around a stable mean that corresponds to personality traits (Fleeson, 2001). However, some basic questions about the nature of these within-person fluctuations in states remain unanswered. For example, to what extent can personality state fluctuations be explained by fluctuations in state affect? Is being more neurotic than usual anything more than feeling more negative affect than usual? Is being more extraverted than usual more than feeling more positive affect than usual? The goal of the present paper is to shed light on these questions in order to build a better foundation for future research examining within-person fluctuations in personality states. Specifically, we examine whether the majority of fluctuations in people's personality states is explained by state negative and positive affect, or whether there is meaningful variance in personality states remaining after accounting for state affect.

\footnotetext{
Funding: The preparation of this manuscript was supported by a grant from the John Templeton Foundation to Matthias Mehl (44245) and two grants from the National Science Foundation to Simine Vazire (BCS-1025330, BCS-1125553). The opinions expressed in this publication are those of the authors and do not necessarily reflect the views of the National Science Foundation or the John Templeton Foundation. The funders had no role in study design, data collection and analysis, decision to publish, or preparation of the manuscript.

* Corresponding author.

Email address: wilson@ucdavis.edu (R.E. Wilson)
}

\subsection{State personality}

In 1936, Allport and Odbert combed through the unabridged English dictionary and identified 18,000 terms that could be used to "distinguish the behavior of one human being from that of another" (as cited in John \& Srivastava, 1999, p. 103). Importantly, Allport and Odbert differentiated between terms that represented "generalized and personalized determining characteristics-consistent and stable modes of an individual's adjustment to his environment" (i.e., traits) and terms that referred to "temporary states, moods, and activities" (i.e., states; as cited in John \& Srivastava, 1999, p. 103) and included only the former in their final taxonomy. In its early years, the field of personality focused on distilling Allport and Odbert's trait terms into a useful taxonomy of traits (Cattell, 1943, 1944). Decades of empirical work on this topic have led to a consensus that five superordinate traits (e.g., the Big Five) adequately capture the principal dimensions of personality along which people differ at the trait level (Costa \& McCrae, 1992; Goldberg, 1981, 1990, 1992), including some productive debate about alternative trait factor structures (e.g., HEXACO, Ashton, Lee, \& Goldberg, 2007; the Big Six, Thalmayer, Saucier, \& Eigenhuis, 2011). The focus on traits spurred a renaissance in personality research and has provided a solid foundation for exploring more complex phenomena (e.g., interpersonal perception, personality development, personality and health, personality and relationships). Personality researchers have recently devoted increased attention to individual differences in states that capture dynamic patterns of thinking, feeling, and behaving (Fleeson, 2001; Fournier, Moskowitz, \& Zuroff, 2008; Slatcher \& Vazire, 2009).

McAdams (1994) famously referred to global traits as 'the psychology of the stranger', and argued that to truly understand a person, we must understand his/her contingent, context-specific patterns of thoughts, feelings, and behavior (and, ultimately, their life narrative). Prominent social-cognitive theories of personality also emphasize 
that the essence of personality is not global, decontextualized traits, but people's idiosyncratic patterns of fluctuations, and the situational factors that trigger these 'if... then' patterns (Mischel \& Shoda, 1995). Yet there has been little research on how much of the fluctuation in personality is at the dynamic, intrapersonal (i.e., within-person) level.

Perhaps the most empirically well-supported social-cognitive model of personality is Fleeson's Whole Trait Model (Fleeson \& Jayawickreme, 2015). This model combines the robust evidence for individual differences in average global traits with the growing evidence that people also vary substantially around these averages. According to this model, personality traits are best conceptualized as density distributions of momentary states. Traditional trait measures capture the average of a person's density distribution - the level at which a person typically falls. However, it is possible to examine the situational and cognitive influences that explain why people fluctuate around their general tendencies, as represented by the mean of a density distribution. For example, Fleeson (2007) found that certain situational cues (e.g., anonymity, task orientation) could explain variation in personality states. If the causes of variance in personality can be explained, it may lead to a better understanding of the processes underlying personality structure and personality development. Individual differences in the underlying causes of personality fluctuations may have important explanatory power, both for predicting outcomes and making sense of people's seemingly inconsistent thoughts, feelings, and behaviors.

Despite the theoretical importance of understanding within-person personality dynamics, few empirical studies had examined this topic. In the last decade, however, new methods and technologies have made it easier to collect and analyze intensive longitudinal data on personality states. The widespread use of smartphones makes collecting Ecological Momentary Assessments (EMA) of personality more convenient. ${ }^{1}$ A typical EMA study will prompt participants to report how they were acting, feeling, or behaving multiple times per day for a number of days or weeks (Barrett \& Barrett, 2001; Csikszentmihalyi \& Larson, 1987; Hektner, Schmidt, \& Csikszentmihalyi, 2007; Hofmann, Baumeister, Förster, \& Vohs, 2012). This approach provides enough information to accurately estimate people's density distributions of personality states (Fleeson, 2001). Alternatively, researchers can use smartphones to passively collect EMA data. For example, the Electronically Activated Recorder (EAR; Mehl, Pennebaker, Crow, Dabbs, \& Price, 2001) provides an observer-based ecologically valid measure of daily behavior that can be used to estimate density distributions of (acoustically-detectable) personality states. However, before these methods can test fundamental questions about dynamic personality processes, we must first ask some basic questions about what we are measuring when we are assessing personality states.

One important possibility to consider is that fluctuations in personality states may merely reflect fluctuations in affect. For example, being more agreeable than usual could be entirely accounted for by feeling better than usual. Before attempting to understand and predict within-person fluctuations in Big Five personality states, we should examine whether these fluctuations can be accounted for by state pos-

\footnotetext{
${ }^{1}$ EMA is often used interchangeably with the phrase 'Experience Sampling Method' (ESM). However, ESM refers to repeatedly asking participant's to complete self-reports whereas EMA is used more broadly to refer to any method that collects intensive repeated measures (Mehl \& Conner, 2011). The findings presented in Section 3 are based on ESM data. However, we chose to use EMA in our Sections 1 and 4 to remain inclusive of all intensive repeated methods.
}

itive and negative affect. Below we review the literature on the association between personality and affect at the trait level, and then discuss whether we should expect to find similar associations between personality and affect at the state level.

\subsection{Associations between personality and affect: trait vs. state levels}

In this paper, we restrict our consideration of personality to the Big Five in order to provide a broad, first pass at our research question. A great deal of research has examined the associations between the Big Five personality traits and positive and negative affect at the trait level. The most intensively studied associations between personality and affect have been the associations between extraversion and positive affect and neuroticism and negative affect (Charles, Reynolds, \& Gatz, 2001; Costa \& McCrae, 1980a; David, Green, Martin, \& Suls, 1997; DeNeve \& Cooper, 1998; Diener \& Lucas, 1999; Diener, Oishi, \& Lucas, 2003; Diener, Suh, Lucas, \& Smith, 1999; Fossum \& Barrett, 2000; Gross, Sutton, \& Ketelaar, 1998; Izard, Libero, Putnam, \& Haynes, 1993; Larsen \& Ketelaar, 1989, 1991; Lucas \& Fujita, 2000; McCrae \& Costa, 1991; Meyer \& Shack, 1989; Rusting, 1999; Schutte, Malouff, Segrera, Wolf, \& Rodgers, 2003; Spain, Eaton, \& Funder, 2000; Suh, Diener, \& Fujita, 1996; Watson \& Clark, 1992). One meta-analysis found that extraversion correlated 0.37 with positive affect (Lucas \& Fujita, 2000). A separate review of the literature found that trait neuroticism correlates strongly with trait negative affect $(r=0.33-0.65$; Wilson \& Gullone, 1999).

Although fewer studies have focused on the other Big Five traits (i.e., agreeableness, conscientiousness, and openness), there is some evidence that trait affect is related to these personality traits as well. Watson and Clark (1992) found that, across four samples, trait negative affect correlated most strongly with neuroticism $(r=0.58)$, followed by agreeableness $(r=-0.23)$, extraversion $(r=-0.20)$, conscientiousness $(r=-0.19)$, and openness $(r=-0.13)$. Trait positive affect was also related to all Big Five traits, correlating most strongly with extraversion $(r=0.58)$, followed by conscientiousness $(r=0.37)$, openness $(r=0.33)$, neuroticism $(r=-0.29)$, and agreeableness $(r=0.21)$. In addition, other research has found that state conscientiousness is positively associated with positive affect (Schutte et al., 2003). In sum, the pattern that emerges based on existing research is that trait affect is an integral component of all Big Five traits.

There is some debate about whether the associations between trait affect and personality traits are strong enough to raise concerns about discriminant validity (Costa \& McCrae, 1980b; Larsen \& Ketelaar, 1989). For example, should extraversion and neuroticism be reconceptualised as trait positive and negative affect, respectively? We do not hope to resolve this debate. Instead, we argue that this literature shows that extraversion and neuroticism have a stronger affective component than the other Big Five traits. This is also supported by Pytlik Zillig et al. (2002), who conducted an analysis of item content in Big Five measures showing that neuroticism had the largest proportion of affect-related items, followed by extraversion and agreeableness.

What do these trait-level findings mean for the state-level associations between personality and affect? As we know from many other domains, we cannot extrapolate from the trait level to the state level (i.e., commit the ecological fallacy). Two variables that are strongly related at the trait level may have no association at the state level, and vice versa. For example, people who are more sociable (a facet of extraversion) may also experience more positive affect (trait-level association), but people may not experience more positive affect when 
they are being more sociable (state-level association). There could be a delayed effect of sociability on positive affect (or of positive affect on sociability), or there could be a third variable causing the association at the trait level (e.g., popularity). Likewise, it is possible that agreeableness and positive affect are strongly linked at the state level, even though the association at the trait level is modest. This could happen if, for example, those high on trait agreeableness are kind all the time, but those low on agreeableness are only kind when they are in a very good mood (a state-level association that would be moderated by trait agreeableness).

Thus, we cannot assume that the associations at the state level will mirror those at the trait level. Instead, we must look to research that directly examines within-person fluctuations in personality and affect. Fortunately, recent work has begun to explore the within-person associations between affect and personality. Research using both experimental and Ecological Momentary Assessment (EMA) has found that people report being happier when they are acting more extraverted than when they are acting more introverted (Fleeson, Malanos, \& Achille, 2002; McNiel, Lowman, \& Fleeson, 2010). In addition, people report feeling more state negative affect when they are acting more neurotic than when they are acting less neurotic (McNiel \& Fleeson, 2006).

As with the trait literature, research on associations between statelevel personality and affect has largely focused on the relations between extraversion and positive affect and neuroticism and negative affect. The only exception, to our knowledge, is research by Ching et al. (2014) that examined the within-person associations between all Big Five personality traits and affect (among other constructs) across five cultures. Across five samples, they found that positive affect covaried positively with extraversion, agreeableness, openness, and, to a lesser extent conscientiousness, and covaried negatively with neuroticism. They also found that negative affect covaried positively with neuroticism and covaried negatively with extraversion, agreeableness, and conscientiousness (Ching et al., 2014, Table 4). However, all personality variables were entered simultaneously into one model (with state affect as the dependent variable), making it difficult to draw conclusions about the associations between each personality construct and affect. In addition, no study has assessed whether there is meaningful variance in personality states remaining after controlling for state affect.

\subsection{Present study}

The goal of the present study is to test whether fluctuations in the Big Five personality states are more than fluctuations in affect. When people are more extraverted, neurotic, agreeable, conscientious, and open than usual, is it more than feeling more positive or negative affect than usual? We tested this by examining whether there was any meaningful within-person variance in personality states remaining after accounting for within-person variance in affect. Thus, we did not take a hypothesis-testing approach but rather an effect estimation approach.

Another aim of our study was to examine whether the amount of within-person variance in personality states explained by affect varies across Big Five domains. Are fluctuations in some Big Five constructs more strongly linked to state affect than others? Based on the evidence presented above, we expected that, among the Big Five, state extraversion would be most strongly related to state positive affect and state neuroticism would be most strongly related to state negative affect at the within-person level.

To test these questions, we collected EMA data on personality and affective states across two studies using different measures of state personality. We then examined the proportion of within-person variance in personality states that could be accounted for by affect. Of course, not all of the within-person variance in personality states is true variance, some of it is error variance. We took a conceptual approach to test whether the residual within-person variance in personality states leftover after accounting for affect is valid variance (i.e., more than error). Specifically, we reasoned that if there was reliable within-person variance in personality leftover after controlling for affect, it should be possible to find another within-person variable (e.g., a characteristic of the situation) that predicts within-person variance in personality states after controlling for affect. For example, if we find that people are less extraverted when they are studying than when they are socializing, independent of their state affect, this suggests that there are meaningful fluctuations in state extraversion that cannot be reduced to state affect. Because our studies contain EMA measures of situational variables, we were able to examine whether including within-person situational variables predicted additional variance in personality states above and beyond positive and negative affect. The specific relations among the situation variables and state personality were not the main focus of these analyses. Rather, we simply used the situation variables we had available to test whether the within-person variance in personality states leftover after accounting for affect could be predicted by relevant situational variables. We describe how we selected the situation variables in the method and results sections below.

The search for non-affective (i.e., situational) predictors of withinperson variance in personality states is a conservative test; even if there is valid within-person variance in Big Five states remaining after accounting for affect, these particular situational variables would not necessarily predict that variance. Nevertheless, we reasoned that, if affect does not predict most of the valid within-person variance in personality states, situational variables should have a good chance of predicting some of the remaining valid variance (Fleeson, 2007). On the other hand, incremental validity claims may be susceptible to increased risk of false positives when the control variable (in this case, affect) is measured imperfectly and observed variables are used (i.e., the model assumes no measurement error in the control variables) (Westfall \& Yarkoni, 2016). Thus, if the situational variables account for state personality above and beyond state affect, these results should be interpreted with caution.

The primary goal of the present study is to understand the nature of personality states. One important step is to establish whether fluctuations in personality states are more than changes in state affect. Understanding the amount of overlap between state personality and affect will further our understanding of the nature of dynamic personality processes and open the door to other important research questions. The present study is designed to quantify this overlap and examine how it may differ for each Big Five domain.

\section{Method}

We used data from two independent studies to test our research questions. For both studies, we report how we determined our sample size, all data exclusions, and all measures examined as part of this project (Simmons, Nelson, \& Simonsohn, 2012). In addition, all R code, data used in the results section, and details regarding other measures collected for the two samples are available on the Open Science Framework: osf.io/xrpjt). Although analyses from these two datasets have been published elsewhere (Bollich, Rogers, \& Vazire, 2015; Solomon \& Vazire, 2014; Wilson, Harris, \& Vazire, 2015; Wilson \& Vazire, 2015), none of the results reported here overlap with any published work; all reported results are original. 


\subsection{Study 1}

\subsubsection{Participants}

Participants were undergraduate students at Washington University in St. Louis who participated in exchange for either course credit or monetary reward ( $\$ 20$ for a two hour in lab session and a one in 15 chance to win an additional \$50 for completing EMA surveys). The current sample $(n=124)$ is a subset of a larger study $(N=208)$, which only includes participants who completed the EMA portion of the study. The EMA portion of the study was added after the study had been running for a semester, explaining the difference between the overall and EMA sample size. The participants $(67 \%$ female) ranged in age from 18 to 36 years $(M=20.1, S D=2.3)$. Self-reports of ethnicity indicate that $54(43.5 \%)$ participants identified as Caucasian, 24 $(19.4 \%)$ as Asian, $10(8.1 \%)$ as Black, $5(4.0 \%)$ as Hispanic, and 31 (25\%) did not report their ethnicity. Participants were recruited via the student Psychology Department participant pool and through flyer advertisements.

\subsubsection{Procedure and materials}

Participants attended a two-hour lab session during which they completed a variety of tasks unrelated to the current research questions. At the conclusion of the in-lab session, the EMA portion of the study was described to the participants. EMA surveys were emailed to participants six times per day for approximately ${ }^{2}$ six days, totalling 34 possible surveys. This repeated-measures design was implemented to provide an ecologically valid measure of personality states and behavior as they occurred in approximately real time (Mehl \& Conner, 2011).

The surveys included an adapted state version of the Ten Item Personality Inventory (TIPI) to assess the Big Five personality states (TIPI; Gosling, Rentfrow, \& Swann, 2003). We also included two single-item measures to assess state positive and negative affect (e.g., "from 5 to $6 \mathrm{pm}$, how much positive (negative) emotion did you experience?"). In addition, the surveys included 16 items assessing characteristics of the situation. To address our research question, we examined the following six situational variables. We assessed whether the participant (1) was working (vs. doing something fun) (2) how much s/he liked the people s/he was with (3) how much s/he wanted to be in the situation, and (4) how much s/he cared about the impression s/ he made (1-5 scale). Finally, we assessed the extent to which the situation was (5) common/familiar to the participant, and (6) constrained the participant's behavior. Many of these situations parallel systematic taxonomies of situations (e.g., Sherman, Rauthmann, Brown, Serfass, \& Jones, 2015). However, we do not claim that these six situations represent a comprehensive list of situations relevant to the Big Five. Rather, these six situations were selected a priori because they seemed likely to explain some variance in the Big Five after controlling for affect, which was the main justification for including them in the analyses.

Participants used a 5-point Likert-type scale for all responses. Participants were asked to rate how they were thinking, feeling, or behaving during the hour just preceding when the survey was sent (e.g.,

\footnotetext{
2 Qualtrics makes it difficult to specify the exact number of surveys sent to each participant. Therefore, we added participants to a Qualtrics Panel once they completed the in-lab session, and each participant received EMA surveys six times a day until removed from the Qualtrics Panel on the seventh day. Therefore, participants may have received a slightly different number of EMA surveys based on the time of day that they finished the in-lab session or the time of day that they were removed from the Qualtrics Panel on the seventh day of the study.
}

the 11 am survey read: "From 10 to 11 am, how 'reserved, quiet' were you?"). The surveys were emailed to participants at exactly $11 \mathrm{am}$, $1 \mathrm{pm}, 3 \mathrm{pm}, 5 \mathrm{pm}, 7 \mathrm{pm}$, and $9 \mathrm{pm}$ using Qualtrics, a survey design program. Text messages were also sent to participants' cellphones at these times to remind participants to complete the surveys. The surveys took 2-3 min to finish and could be completed on a smartphone or any other device with access to the Internet.

Participants completed a total of 2809 EMA surveys. To ensure a high level of quality for the EMA data, a number of exclusion criteria, which were determined prior to analyzing data, were applied. Specifically, EMA surveys were excluded from analysis if: (a) a survey was completed more than two hours after it was sent; (b) the participant indicated that they were sleeping during the hour block; (c) less than $75 \%$ of the items on the survey were completed; or (d) if the participant gave the same response for $70 \%$ or more of the items. Based on these criteria, 2351 surveys qualified for inclusion (84.1\%). Of the 130 participants who participated in the EMA portion, 124 participants completed at least one survey that met our criteria (mean number of surveys completed $=19.0, S D=10.2$ ).

\subsection{Study 2}

The data used for the Study 2 are part of the longitudinal Personality and Interpersonal Roles Study (PAIRS; Vazire et al., 2015). The data used in Study 2 are from the initial wave of data collection.

\subsubsection{Participants}

Participants in Study $2(\mathrm{~N}=434)$ were recruited from the Washington University in St. Louis student population. However, an effort was made to recruit students outside of the Psychology Department participant pool through flyer advertisements and classroom announcements. The current sample $(n=415)$ includes participants who completed at least one EMA survey that met our inclusion criteria (described below). Participants (68\% female) ranged in age from 18 to 32 years $(M=19.3, S D=2.0)$. They were paid $\$ 20$ for the in-lab portion of the first assessment and entered into a lottery with the opportunity to win $\$ 100$ for completing EMA surveys (odds of winning were 1 in 10 if all EMA surveys were completed). Self-reports of ethnicity indicate that $210(50 \%)$ participants identified as Caucasian, $92(22 \%)$ as Asian, $40(10 \%)$ as Black, $59(14 \%)$ as other, and $10(2 \%)$ did not report their ethnicity.

\subsubsection{Procedure and materials}

The tasks completed by participants in Study 2 were similar to the tasks completed by participants in Study 1. The first portion of the study involved a two-hour laboratory session during which participants completed a variety of questionnaires and a series of other tasks unrelated to the current research questions. After the laboratory session, participants were instructed on the EMA portion of the study. Participants were emailed surveys four times per day for approximately 14 days, for a total of 59 possible surveys per participant. As in Study 1, text messages were sent to participants' cellphones to remind participants when to complete the surveys.

Unlike Study 1, the personality items were drawn from the BFI-44 (John, Naumann, \& Soto, 2008). The shortened BFI scale was comprised of two items per construct taken from the original BFI-44, making sure that each item (a) made sense at the state level; (b) assessed a different facet of the respective Big Five construct; (c) avoided difficult vocabulary words, and (d) had a comparatively high item total correlation (see Appendix A). The item stems were changed to refer to the specific time period covered by the EMA survey (e.g., "From 2 to $3 \mathrm{pm}$, how lazy were you?") and responses were 
given on a 5-point Likert-type scale. Unlike Study 1, the items used to measure agreeableness (i.e., 'rude' and 'considerate, kind') were only assessed if the participant indicated that they were interacting with others. Study 2 did not include EMA items for the Big Five construct of openness. Thus, the EMA surveys in Study 2 measured personality states for four of the Big Five personality dimensions.

As in Study 1, we included two single-item measures to assess state positive and negative affect (e.g., "from 8 to $9 \mathrm{pm}$, how much positive (negative) emotion did you experience?"). These affective items were added after the study began, and the first 55 participants did not complete the state affect items. The surveys included 36 items designed to measure the situational context and daily behaviors that occurred during the specified hour block. To address our research question, we examined the same six situations variables as in Study 1 with one additional situational variable: participants' perception of their status relative to their interaction partner.

All responses were made on a 5-point Likert-type scale, except the 'Studying/working' item, which was a yes/no question in Study 2. Participants were asked to rate how they were thinking, feeling, or behaving during the hour just preceding when the survey was sent (e.g., the 11 am survey read: "From 10 to $11 \mathrm{am}$, how 'reserved, quiet' were you?"). The surveys were emailed to participants at exactly $12 \mathrm{pm}$, $3 \mathrm{pm}, 6 \mathrm{pm}$, and $9 \mathrm{pm}$ using Qualtrics. Text messages were sent to participants' phones at these times as a reminder to complete the surveys. The surveys took 3-4 min to complete and could be completed on a smartphone or any other device with access to the Internet.

Participants completed a total of 15,563 EMA surveys. As with Study 1, a number of exclusion criteria were applied, and these were determined before analyzing the data. Specifically, EMA surveys were excluded from analysis if: (a) a survey was completed more than three hours after it was sent (the exclusion criterion differs from Study 1 because the surveys were spaced further apart in Study 2); (b) the participant indicated that they were sleeping during the hour block; (c) less than $75 \%$ of the items on the survey were completed; or (d) if the participant gave the same response for $70 \%$ or more of the items. Based on these criteria, 11,540 surveys qualified for inclusion $(75.0 \%)$. Of the 434 participants who participated in the EMA portion, 415 participants completed at least one survey that met our criteria (mean number of surveys completed per participant $=29.7, S D=15.2$ ).

Table 1

Proportion of variance in personality and affect at the within- and between-person level.

\begin{tabular}{|c|c|c|c|c|c|c|c|c|c|c|c|c|}
\hline \multirow[t]{3}{*}{ Measures } & \multicolumn{6}{|l|}{ Study 1} & \multicolumn{6}{|l|}{ Study 2} \\
\hline & $\begin{array}{l}\text { Internal } \\
\text { consis }\end{array}$ & $n$ & & $M$ & $S D$ & & Internal consis & $n$ & & $M$ & $S D$ & \\
\hline & & Level 1 & Level 2 & & $\begin{array}{l}\text { Between- } \\
\text { person }\end{array}$ & $\begin{array}{l}\text { Within- } \\
\text { person }\end{array}$ & & Level 1 & Level 2 & & Between persons & Within persons \\
\hline Extraversion & 0.63 & 2351 & 124 & 2.95 & $0.36(26 \%)$ & $1.00(74 \%)$ & 0.67 & 11,501 & 415 & 2.79 & $0.39(26 \%)$ & $1.12(74 \%)$ \\
\hline Neuroticism & 0.71 & 2351 & 124 & 2.06 & $0.48(0.39 \%)$ & $0.73(61 \%)$ & 0.51 & 11,502 & 415 & 2.41 & $0.48(36 \%)$ & $0.86(64 \%)$ \\
\hline Agreeableness & 0.19 & 2351 & 124 & 3.68 & $0.40(38 \%)$ & $0.64(62 \%)$ & 0.20 & 9530 & 415 & 3.98 & $0.40(42 \%)$ & $0.54(58 \%)$ \\
\hline Conscientiousness & 0.41 & 2351 & 124 & 3.64 & $0.41(36 \%)$ & $0.72(64 \%)$ & 0.24 & 11,501 & 415 & 3.62 & $0.46(37 \%)$ & $0.80(63 \%)$ \\
\hline Openness & 0.29 & 2351 & 124 & 3.13 & $0.41(36 \%)$ & $0.74(64 \%)$ & - & - & - & - & - & - \\
\hline Positive affect & - & 2349 & 124 & 3.42 & $0.41(33 \%)$ & $0.85(67 \%)$ & - & 9478 & 360 & 3.41 & $0.46(35 \%)$ & $0.86(65 \%)$ \\
\hline Negative affect & - & 2350 & 124 & 2.16 & $0.48(37 \%)$ & $0.83(63 \%)$ & - & 9478 & 360 & 2.15 & $0.47(34 \%)$ & $0.89(66 \%)$ \\
\hline
\end{tabular}

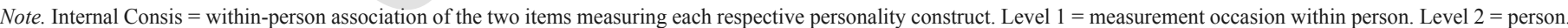

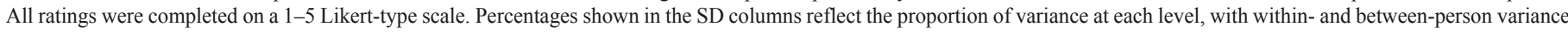

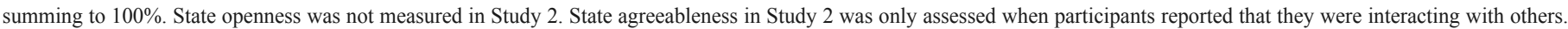

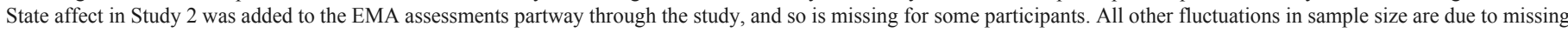
data (i.e., non-responses).

\section{Results}

\subsection{Within- and between-person variance in personality and affect}

To account for the nested structure of the data (i.e., EMA survey responses nested within participants), all analyses were run using multilevel modeling. Multilevel modeling estimates within- and betweenperson effects simultaneously (Krull \& MacKinnon, 2001) while accounting for any missing data (Snijders \& Bosker, 1999). We modeled all MLM analyses in lme4, a package in R (Bates, Maechler, Bolker, \& Walker, 2014).

Before testing our main research question, we first assessed the internal consistency of the TIPI and BFI-short Big Five items used in the EMA surveys for each study. As shown in Table 1, the within-person item-level correlations for the Big Five ranged from 0.19 to 0.71, indicating that, for some constructs, items hung together more strongly than for others. The TIPI and BFI-short scales were designed to capture broad domains with two items and maximize validity, not create a scale with high internal reliability (Gosling et al., 2003). Therefore, we report the aggregated results for the Big Five based on the two items given that such composites can still be appropriate despite low internal consistency (Gosling et al., 2003). Second, we assessed the proportion of variance in personality states at the between- and within-person levels. The overall variance is the sum of the between- and within-person variance (see SD columns in Table 1). To better understand the proportion of variance at the within- and between-person levels, we followed the procedure used by Church et al. (2013) to calculate an intraclass correlation (ICC) and divided the variance at each level by the total variance. Results by construct are presented in Table 1 . These results are consistent with previous research examining the proportion of within- and between-person variance in personality and affect (Church et al., 2013; Fleeson, 2001). Specifically, the results showed that there is more within-person variance than between-person variance (though the within-person variance also contains all the error in each model), and that the proportion of within-person variance in personality states was as similar to the proportion of within-person variance in affect.

3.2. How much of the variance in personality states can be accounted for by state affect?

Next, we examined the extent to which fluctuations in personality states can be statistically accounted for by fluctuations in affect. To 
do so, we ran a series of multi-level models predicting each of the Big Five personality constructs from (a) positive affect; (b) negative affect, and (c) positive and negative affect entered simultaneously. All predictors were person-centered, and all models were random effects models (i.e., intercepts and slopes were allowed to vary), and we report parameter estimates with robust standard errors. Ideally, we would report standardized effect sizes that could be compared across models. However, the standardization of within-person coefficients in multi-level modeling is more complicated than single-level multiple regression because of the nested structure of the data. One option was to standardize across all completed surveys, but such an approach ignores the hierarchical structure of the data, alters the variance components of the model, changes the $p$-values slightly, and does not set the within-person standard deviation for each participant to 1.0 (Hox, 2010; Nezlek, 2012). A second option was to standardize within each person but this erases between-person differences in item variance from the model (Nezlek, 2012). Therefore, we have followed the most common recommendation of multi-level experts and reported the unstandardized coefficients in Table 2 (Hox, 2010; Nezlek, 2012).

The results from these models are presented in Table 2. Each Big Five personality construct was modeled as a function of positive affect, negative affect, and positive and negative affect, for Study 1 and Study 2 . The within-person relationship between personality and positive and negative affect were examined using the following model:

$$
\begin{gathered}
y_{i j}=\beta_{0 j}+\beta_{1 j}(\mathrm{PA})+\beta_{2 j}(\mathrm{NA})+r_{i j} \\
\beta_{0 j}=\gamma_{00}+u_{0 j} \\
\beta_{1 j}=\gamma_{10}+u_{1 j} \\
\beta_{2 j}=\gamma_{20}+u_{2 j}
\end{gathered}
$$

In this model, $\beta_{0 j}$ is a random coefficient representing the intercept of state personality for person $j$ across all completed EMA data points; $\beta_{1 j}(\mathrm{PA})$ is a random slope coefficient representing the state level within-person relationship between positive affect and each respective personality state; $\beta_{2 j}(\mathrm{NA})$ is a random slope coefficient representing the state level within-person relationship between negative affect and each respective personality state; $r_{i j}$ represents the error term in the model (Nezlek \& Plesko, 2001). Time was not included in our models because there was no theoretical reason to expect time to influence personality states or affect differentially.
Because EMA items were answered on a 5-point Likert-type scale, an increase of one unstandardized unit represents a one-point increase on this 5-point scale. For example, the results for extraversion show that, on average, for every 1 unit increase (on a 1-5 scale) in positive affect, extraversion increased by 0.64 units in Study 1 and 0.61 units in Study 2. Because these coefficients are unstandardized, it is inadvisable to compare the magnitude of effects across rows (i.e., across models) as each personality state DV has a different amount of withinperson variance. For example, extraversion has more within-person variance than the other domains (see Table 1 for specific variance estimates). However, we can compare the coefficients (e.g., positive and negative affect) within a given row. Fig. 1 also shows a visualization of the relationship between positive and negative affect for each of the Big Five constructs.

In addition, although we cannot compare the coefficients across models (i.e., on different rows of Table 2), we can compare the proportion of variance explained by the different models. To do this, we calculated how much of the variance in state personality (e.g., state extraversion) was explained when positive and negative affect were included simultaneously as predictors in our MLM models. More specifically, we modeled the respective and joint associations between state positive and negative affect (IVs) and state personality (DV) for each Big Five construct.

Finally, we assessed the proportion of variance explained using marginal $R^{2}\left(R_{m}^{2}\right)$ and conditional $R^{2}\left(R_{c}^{2}\right)$. The $R_{m}^{2}$ indicates the proportion of variance explained for only the fixed effects of the model, whereas the $\mathrm{R}_{\mathrm{c}}^{2}$ can be interpreted as the overall proportion of explained variance when including the random effect estimates (Nakagawa \& Schielzeth, 2013; Sherman et al., 2015). The discrepancy between $\mathrm{R}_{\mathrm{m}}^{2}$ and $\mathrm{R}_{\mathrm{c}}{ }_{\mathrm{c}}$ gives an indication of the variability accounted for by allowing slopes to vary across individuals. For example, although the fixed effect (i.e., main effect) of positive affect explains essentially no variance in conscientiousness $\left(\mathrm{R}_{\mathrm{m}}^{2}=0.01\right.$; Study $2: R_{m}^{2}=0.01$ ), the random effect estimates of positive affect explain relatively large amount of variance in conscientiousness (Study 1: $\mathrm{R}_{\mathrm{c}}^{2}=0.41$; Study $2: \mathrm{R}_{\mathrm{c}}^{2}=0.29$ ). This suggests that positive affect accounts for $29-41 \%$ of the variance in state conscientiousness for each person, but the association between positive affect and conscientiousness differs across individuals, hence the low marginal $\mathrm{R}^{2}$ $\left(\mathrm{R}_{\mathrm{m}}^{2}=0.01\right.$; Study $\left.2: \mathrm{R}_{\mathrm{m}}^{2}=0.01\right)$. Despite the usefulness of $\mathrm{R}_{\mathrm{m}}^{2}$ and

\begin{tabular}{|c|c|c|c|c|c|c|c|c|c|c|}
\hline & \multicolumn{2}{|c|}{ Positive affect } & \multicolumn{4}{|c|}{ Negative affect } & \multicolumn{3}{|c|}{ Positive $\left(b_{01}\right) \&$ Negative $\left(b_{02}\right)$ affect } & \multirow[b]{2}{*}{$R_{c}^{2}$} \\
\hline & $b_{01}$ & $R_{m}^{2}$ & $R_{c}^{2}$ & $b_{01}$ & $R_{m}^{2}$ & $R_{c}^{2}$ & $b_{01}$ & $b_{02}$ & $R_{m}^{2}$ & \\
\hline \multicolumn{11}{|l|}{ Study 1} \\
\hline Extraversion & $0.64^{* *}$ & 0.25 & 0.40 & $-0.29^{* *}$ & 0.05 & 0.19 & $0.64^{* *}$ & 0.00 & 0.25 & 0.40 \\
\hline Neuroticism & $-0.33^{* *}$ & 0.10 & 0.46 & $0.46^{* *}$ & 0.18 & 0.55 & $-0.15^{* *}$ & $0.41^{* *}$ & 0.21 & 0.57 \\
\hline Agreeableness & $0.34 * *$ & 0.14 & 0.46 & $-0.32 * *$ & 0.12 & 0.44 & $0.24^{* *}$ & $-0.21^{* *}$ & 0.18 & 0.50 \\
\hline Conscientiousness & $0.09^{* * *}$ & 0.01 & 0.41 & $-0.10^{* *}$ & 0.01 & 0.27 & $0.05^{*}$ & $-0.07^{*}$ & 0.01 & 0.28 \\
\hline Openness & $0.36^{* *}$ & 0.12 & 0.41 & $-0.20 * *$ & 0.04 & 0.31 & $0.34^{* *}$ & -0.03 & 0.12 & 0.41 \\
\hline \multicolumn{11}{|l|}{ Study 2} \\
\hline Extraversion & $0.61^{* *}$ & 0.19 & 0.32 & $-0.28^{* *}$ & 0.04 & 0.17 & $0.62^{* *}$ & $0.02^{* *}$ & 0.19 & 0.33 \\
\hline Neuroticism & $-0.46^{* *}$ & 0.15 & 0.42 & $0.53^{* *}$ & 0.22 & 0.48 & $-0.25^{* *}$ & $0.41^{* *}$ & 0.25 & 0.52 \\
\hline Agreeableness & $0.18^{* *}$ & 0.05 & 0.42 & $-0.17^{* *}$ & 0.05 & 0.43 & $0.12^{* *}$ & $-0.11^{* *}$ & 0.07 & 0.45 \\
\hline Conscientiousness & $0.12 * *$ & 0.01 & 0.29 & $-0.06^{* *}$ & 0.00 & 0.28 & $0.11^{* *}$ & $-0.02^{* *}$ & 0.01 & 0.30 \\
\hline
\end{tabular}
$\mathrm{R}^{2}$, as with other measures of $\mathrm{R}^{2}$, we do not know how much of the

Table 2

Within-person associations between state affect (IVs) and state personality (DV).

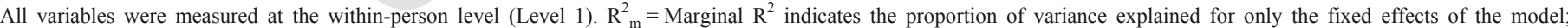

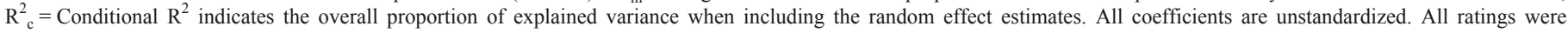
completed on a 1-5 scale. All predictors were person-centered prior to analysis to control for between person variance in affect. All predictors were allowed to randomly vary.

$* p<0.05$.

** $p<0.01$. 


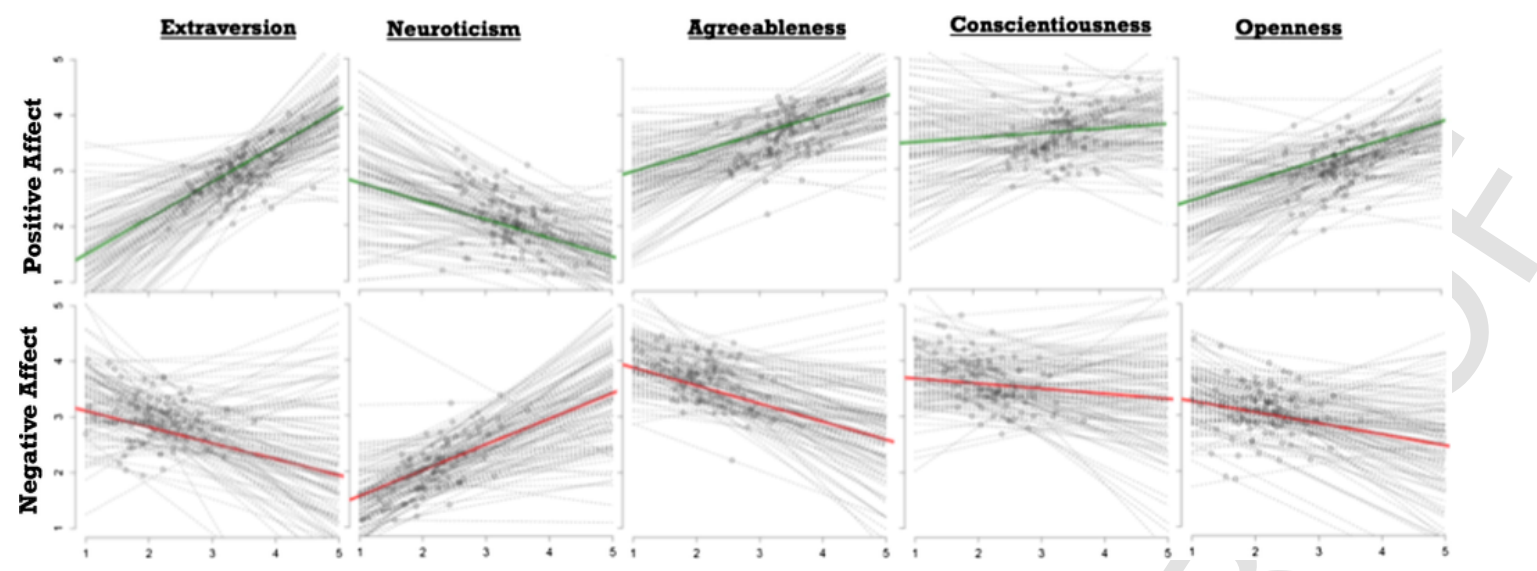

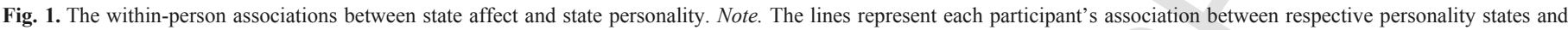
positive affect (top row) and negative affect (bottom row), with the fixed effect displayed as the bold line in each spaghetti plot. Data from Study 1 ( $\mathrm{N}=124$ ).

within-person variance in each personality state is true (vs. error) variance and therefore interpret these estimates with caution.

\subsubsection{Extraversion}

Consistent with previous research, we found that within-person fluctuations in state extraversion were strongly associated with fluctuations in state positive affect. State extraversion was also associated with state negative affect, but across both studies, this association became negligible when positive and negative affect were entered simultaneously as predictors (see last four columns of Table 2). That is, at the within-person level, state extraversion shares more unique variance with state positive than negative affect. These results suggest that, to a large extent, state extraversion covaries within-person with state positive affect - when people experience positive affect, they are also likely to report being more extraverted. However, affect did not explain all of the within-person variance in extraversion $\left(\mathrm{R}_{\mathrm{c}}^{2}=0.40\right.$ and 0.33 in Studies 1 and 2, respectively). These results are quite consistent across the two studies, despite different items being used to measure state extraversion.

\subsubsection{Neuroticism}

Consistent with previous research, we found that within-person fluctuations in neuroticism are strongly associated with fluctuations in both state positive and state negative affect. The associations with negative affect were, descriptively, somewhat larger than with positive affect, but both predictors remained significant when entered simultaneously. Our results suggest that, to a large extent, state neuroticism covaries with state affect - when people experience more negative affect and less positive affect, they are also likely to report being more neurotic. Affect explained a large proportion of the within-person variance in neuroticism $\left(\mathrm{R}_{\mathrm{c}}^{2}=0.57\right.$ and 0.52 in Studies 1 and 2, respectively). These results were consistent across both studies despite different items being used to assess neuroticism. Because we do not know how much of the within-person variance in neuroticism is true variance (vs. error), we cannot tell whether affect is accounting for all the valid within-person variance in neuroticism, or whether there is some valid variance leftover, but in any case the amount of overlap between state neuroticism and state affect is very high.

\subsubsection{Agreeableness}

Our results for state agreeableness suggest that people are more agreeable when they are experiencing more positive and less negative affect. These two associations (with positive and negative affect, re- spectively) are independent of each other - both state positive and state negative affect remain significant predictors of state agreeableness when entered as predictors simultaneously. These results also show that when both positive and negative affect are entered simultaneously, more variance is explained than when either is entered alone. Affect explained a large proportion of the within-person variance in state agreeableness $\left(\mathrm{R}_{\mathrm{c}}^{2}=0.50\right.$ and 0.45 in Studies 1 and 2, respectively). Once again, the results are consistent across both studies despite different items being used to measure state agreeableness, and once again, we cannot tell whether there is valid within-person variance in agreeableness leftover despite the high degree of overlap with affect.

\subsubsection{Conscientiousness}

Our results for conscientiousness suggest the people, on average, do not tend to be more or less conscientious as a function of their affect. That is, the fixed effects (i.e., average slopes) between state conscientious and state affect at the within-person level were quite small. However, this could obscure strong but opposing within-person associations, such that some people are more conscientious when they are experiencing more positive affect whereas other people are more conscientious when they are experiencing less positive affect. This is consistent with the conditional $\mathrm{R}^{2}$ coefficients which indicated that positive and negative affect explained a sizable proportion of variance at the within-person level when random effects were included (Study 1: $\mathrm{R}_{\mathrm{c}}^{2}=0.28$ and 0.30 in Studies 1 and 2, respectively). However, even in the conditional models much of the within-person variance in conscientiousness remains unexplained after accounting for affect, and these results are quite consistent across the two studies.

\subsubsection{Openness}

Because we did not measure state openness in Study 2, the estimates for openness are based on the Study 1 sample. We found that within-person fluctuations in openness were associated with fluctuations in positive affect. State openness was also associated with state negative affect, but this association became much smaller and non-significant when positive and negative affect were entered simultaneously as predictors. That is, state openness shares more unique variance at the within-person level with state positive affect than with state negative affect. Our results also show that the proportion of variance in state openness that is explained by positive affect alone $\left(\mathrm{R}_{\mathrm{c}}^{2}=0.41\right)$ is very similar to the proportion of variance in state openness that is explained jointly by positive and negative affect $\left(\mathrm{R}_{\mathrm{c}}^{2}=0.41\right)$. These results suggest that when people experience a lot 
of positive affect, they are also likely to report being more open to new experiences. However, some of the within-person variance in openness remains unexplained after accounting for affect.

\subsection{Is there meaningful variance in personality states leftover after accounting for affect?}

The results in Section 3.2 suggest that the state Big Five domains vary in the extent to which they are associated with affect at the within-person level. However, for all Big Five domains, a substantial amount of within-person variance could not be accounted for by fluctuations in affect. It is important to know how much, if any, of the residual within-person variance in personality states is meaningful (i.e., true) variance. An indirect (and conservative) way of testing this possibility is to predict the residual variance with variables other than affect.

We attempted to predict residual personality state variance using the EMA situation variables available to us. Specifically, we identified situation variables that should exert a strong influence on college students' personality states and then tested whether these situation variables predicted fluctuations in Big Five states above and beyond what was already predicted by affect. If the situation variables were significant predictors of within-person fluctuations in personality states above and beyond affect, this suggests that there is meaningful withinperson variance in personality states leftover after accounting for state affect. We first identified, a priori, one situation variable that we reasoned should influence a broad range of personality states: whether a student was studying/working. We tested five models, where each model predicted one of the Big Five personality states from positive affect, negative affect, and studying/working entered simultaneously.

\subsubsection{Studying/working}

Before testing our key models that include studying/working, positive affect, and negative affect predicting the Big Five personality states, we needed to examine how studying/working was related to state affect. For studying/working to serve our purposes, it should not be strongly related to affect. To test this, we ran two multi-level models, predicting state positive affect and state negative affect (DVs) from studying/working (IV). These results, which are presented in the first data column of Table 3 (we explain the other data columns in the next section), indicate that studying/working and affect are weakly to moderately associated at the state level, and do have some non-shared variance. Therefore, studying/working has the potential to predict state personality above and beyond.

Next, we needed to establish whether studying/working predicted within-person fluctuations in each Big Five domain. We ran a series of multilevel models predicting the Big Five states from studying/working (i.e., with no other predictors in the model). Again, intercepts and slopes were allowed to vary. Table 4 shows that withinperson fluctuations in studying/working were significantly associated with within-person fluctuations in all of Big Five states across both studies (see first data column). Specifically, when participants were studying/working, they reported being less extraverted, less agreeable, more conscientious, more neurotic, and less open than when they were not studying/working. This suggests that we succeeded in identifying a situational variable that was associated with personality states.

We ran a series of multilevel models predicting each Big Five personality state from positive affect, negative affect and studying/ working - all entered simultaneously, with all intercepts and slopes allowed to vary. The results in the sixth data column of Table 4 show that, in both Study 1 and 2, studying/working predicted extraversion and conscientiousness above and beyond what was predicted by affect. The addition of studying/working as a predictor of conscientiousness, along with positive and negative affect, increased the amount of variance explained by $7 \%$ in Study 1 (from $R_{c}^{2}=0.28$ to $R_{c}^{2}=0.35$; see Table 2 for reference) and $4 \%$ in Study 2 (from $R_{c}^{2}=0.30$ to $R^{2}{ }_{c}=0.34$ ). However, the addition of studying/working as a predictor of extraversion, along with positive and negative affect, only increased the amount of variance explained by $4 \%$ in Study 1 (from $R^{2}{ }_{c}=0.40$ to $R_{c}^{2}=0.44$; see Table 2 for reference) and $2 \%$ in Study 2 (from $R_{c}^{2}=0.33$ to $R_{c}^{2}=0.35$ ). Study 1 found that studying/working did not predict state neuroticism above and beyond affect, but Study 2 did find a significant association $\left(b_{03}=0.23, p<0.001\right)$; however, the addition of studying/working as a predictor, along with positive and negative affect, only increased the amount of variance explained for neuroticism by $2 \%$ in Study 2 (from $R^{2}{ }_{c}=0.52$ to $R_{c}^{2}=0.54$ ), indicating a small to trivial effect. These results indicate that studying/working does not explain much variance in states above and beyond affect for most of the Big Five personality states, except conscientiousness (though it is important to remember that this model assumes no error in our measurement of affect, and thus may overestimate the incremental predictive validity of the situation variable; Westfall \& Yarkoni, 2016). This suggests that state conscientiousness may not be merely a function of affect but can perhaps also be pre-

Table 3

Situation variables and the associations with state positive and negative affect.

\begin{tabular}{|c|c|c|c|c|c|c|c|}
\hline & Studying/working & Liking others & Want to be there & Status & Care about impr. & Common/familiar & Constraining \\
\hline & $b_{01}$ & $b_{01}$ & $b_{01}$ & $b_{01}$ & $b_{01}$ & $b_{01}$ & $b_{01}$ \\
\hline \multicolumn{8}{|l|}{ Study 1} \\
\hline Positive affect & $-0.29 * *$ & $0.35^{* *}$ & $0.40^{* * *}$ & - & $0.13^{* *}$ & 0.04 & $-0.24^{* *}$ \\
\hline Negative affect & $0.15^{* *}$ & $-0.15^{*}$ & $-0.26^{* *}$ & - & -0.03 & $-0.13^{* *}$ & $0.17^{* *}$ \\
\hline \multicolumn{8}{|l|}{ Study 2} \\
\hline Positive affect & $-0.34^{* *}$ & $0.35^{* *}$ & $0.42^{* *}$ & $0.11^{* *}$ & $0.19^{* *}$ & $0.04^{* *}$ & $-0.20^{* *}$ \\
\hline Negative affect & $0.22^{* *}$ & $-0.22^{* *}$ & $-0.33^{* *}$ & -0.03 & $-0.10^{* *}$ & $-0.09^{* *}$ & $0.17^{* *}$ \\
\hline
\end{tabular}

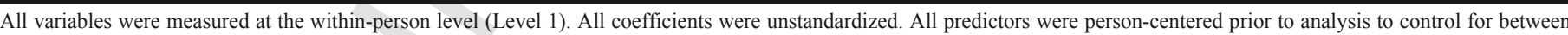

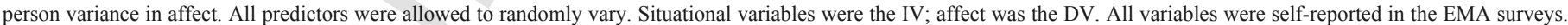

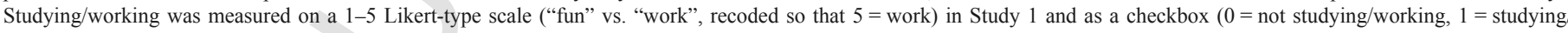

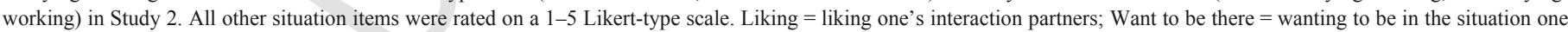

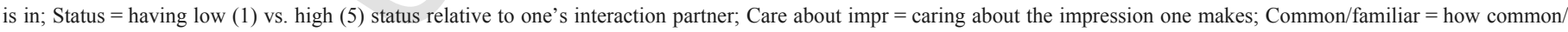
familiar the situation is; Constraining = how much the situation constrains one's behavior.

${ }^{*} p<0.05$.

** $p<0.01$. 
Table 4

Studying/working as a predictor of fluctuations in big five states.

\begin{tabular}{lccccccccc}
\hline \multicolumn{1}{c}{$\begin{array}{l}\text { Studying/working } \\
\left(b_{01}\right)\end{array}$} & \multicolumn{7}{c}{$\begin{array}{l}\text { PA }\left(b_{01}\right) \& \text { NA }\left(b_{02}\right) \& \text { studying/ } \\
\text { Working }\left(b_{03}\right)\end{array}$} \\
\hline & $b_{01}$ & $R^{2}{ }_{m}$ & $R^{2}{ }_{c}$ & $b_{01}$ & $b_{02}$ & $b_{03}$ & $R^{2}{ }_{m}$ & $R_{c}^{2}$ \\
\hline Study 1 & & & & & & & & \\
Extraversion & $-0.29^{*}$ & 0.14 & 0.29 & $0.52^{*}$ & 0.01 & $-0.14^{*}$ & 0.27 & 0.44 \\
Neuroticism & $0.08^{*}$ & 0.01 & 0.34 & $-0.17^{*}$ & $0.40^{*}$ & -0.03 & 0.20 & 0.59 \\
Agreeableness & $-0.11^{*}$ & 0.04 & 0.35 & $0.23^{*}$ & $-0.20^{*}$ & -0.01 & 0.17 & 0.52 \\
Conscientiousness & $0.10^{*}$ & 0.03 & 0.28 & $0.18^{*}$ & $-0.08^{*}$ & $0.16^{*}$ & 0.07 & 0.35 \\
Openness & $-0.13^{*}$ & 0.05 & 0.33 & $0.31^{* *}$ & -0.04 & -0.04 & 0.13 & 0.43 \\
Study 2 & & & & & & & & \\
Extraversion & $-0.50^{* *}$ & 0.04 & 0.17 & $0.59^{* *}$ & 0.02 & $-0.29^{* *}$ & 0.20 & 0.35 \\
Neuroticism & $0.40^{* *}$ & 0.04 & 0.30 & $-0.22^{* *}$ & $0.40^{* *}$ & $0.23^{* *}$ & 0.26 & 0.54 \\
Agreeableness & $-0.06^{* *}$ & 0.00 & 0.36 & $0.13^{* *}$ & $-0.11^{* *}$ & 0.02 & 0.07 & 0.45 \\
Conscientiousness & $0.26^{* *}$ & 0.02 & 0.29 & $0.14^{* *}$ & -0.02 & $0.31^{* *}$ & 0.04 & 0.34 \\
\hline
\end{tabular}

All variables were measured at the within-person level (Level 1). $\mathrm{R}_{\mathrm{m}}^{2}=$ Marginal $\mathrm{R}^{2}$ indicates the proportion of variance explained for only the fixed effects of the model; $\mathrm{R}^{2}=$ Conditional $\mathrm{R}^{2}$ indicates the overall proportion of explained variance when including the random effect estimates. All coefficients are unstandardized. All predictors were person-centered prior to analysis to control for between person variance in affect. All predictors were allowed to randomly vary. PA = Positive affect. $\mathrm{NA}=$ Negative affect. Situational variables and affect were the IVs, personality states were the DV. Studying/working was measured on a 1-5 Likert-type scale ("fun" vs. "work") in Study 1 and as a checkbox ( $0=$ not studying/working, 1 = studying/working) in Study 2.

${ }^{*} p<0.05$.

*** $p<0.01$.

dicted by relevant situational variables, specifically, whether a person is studying/working. The results for extraversion and neuroticism were small but provided some tentative evidence that variance for these constructs may be explained by situations such as studying/ working; however, the effects for agreeableness and openness provided no evidence that studying/working influenced these personality states, beyond what was already explained by affect; these null results do not determine whether there is meaningful within-person variance in state agreeableness and openness remaining after accounting for affect.

\subsubsection{Other situation variables}

The analyses with studying/working were especially inconclusive for agreeableness and openness. Studying/working not predicting fluctuations in these personality states above and beyond affect could mean that (a) affect explains all of the meaningful within-person variance in these constructs, or (b) we have not identified the right situation variable(s) to predict the meaningful leftover variance. Thus, we conducted further tests to examine whether other situation variables could predict within-person variance in state agreeableness and openness. Of course, the more models we test, the more we are at risk of Type I errors. Thus, the results presented below should be interpreted with caution (as should all results, but these even more so).

We selected additional situation variables that were targeted specifically to predict fluctuations in agreeableness and openness. To attempt to predict fluctuations in state agreeableness, we used the following situation variables: how much the participant reported liking the people $\mathrm{s} / \mathrm{he}$ was with, how much the participant reported s/he wanted to be in the situation, the participant's report of his/her status relative to his/her interaction partner(s), and how much the participant reported caring about the impression $\mathrm{s} / \mathrm{h}$ made. To attempt to predict fluctuations in state openness, we used the following situation variables: how common/familiar the participant reported the situation was, and how much the participant reported that the situation constrained his/her behavior. These situation variables were measured as part of the EMA surveys and were measured on a 5-point Likert-type scale. The associations between these situation variables and affect are presented in Tables 5 and 6 .

\subsubsection{Predicting fluctuations in agreeableness}

The results in Table 5, column 1, show that participants reported being more agreeable when they (a) were interacting with others that they liked, (b) wanted to be in the situation they were in, and (c) cared about the impression they made. These effects became small but mostly remained significant once affect is included in the model (0.03-0.07), and the pattern appears robust across both studies. The relative status of the people with whom they were interacting did not predict agreeableness. Despite the initial evidence that some of our selected situations explained variance in state agreeableness, a comparison of the $\mathrm{R}_{\mathrm{c}}^{2}$ for the final models in Table 5 (last column) compared to the $\mathrm{R}_{\mathrm{c}}^{2}$ when only positive and negative affect were included

Table 5

Within-person associations between situations, affective states, and agreeableness.

\begin{tabular}{|c|c|c|c|c|c|c|c|c|}
\hline & \multicolumn{3}{|l|}{ Liking } & \multicolumn{5}{|c|}{ PA \& NA \& Liking } \\
\hline & $b_{01}$ & $R_{m}$ & $R_{c}$ & $b_{01}$ & $b_{02}$ & $b_{03}$ & $R_{m}$ & $R_{c}$ \\
\hline $\begin{array}{l}\text { S1: } \\
\text { Agreeableness }\end{array}$ & $0.13^{* *}$ & 0.02 & 0.28 & $0.19^{* *}$ & $-0.26^{* *}$ & 0.03 & 0.18 & 0.51 \\
\hline \multirow[t]{3}{*}{$\begin{array}{l}\text { S2: } \\
\text { Agreeableness }\end{array}$} & $0.12 * *$ & 0.03 & 0.37 & $0.10^{* *}$ & $-0.11^{* *}$ & $0.06^{* *}$ & 0.07 & 0.44 \\
\hline & \multicolumn{3}{|c|}{ Wanting } & \multicolumn{5}{|c|}{ Positive \& Negative \& Wanting } \\
\hline & $\begin{array}{l}b_{01} \\
0.18^{* *}\end{array}$ & $\begin{array}{l}R_{m} \\
0.07\end{array}$ & $\begin{array}{l}R_{c} \\
0.38\end{array}$ & $\begin{array}{l}b_{01} \\
0.22^{* *}\end{array}$ & $\begin{array}{l}b_{02} \\
-0.20^{* * *}\end{array}$ & $\begin{array}{l}b_{03} \\
0.03^{*}\end{array}$ & $\begin{array}{l}R_{m} \\
0.17\end{array}$ & $\begin{array}{l}R_{c} \\
0.52\end{array}$ \\
\hline Agreeableness & & & & & & & & \\
\hline \multirow[t]{3}{*}{$\begin{array}{l}\text { S2: } \\
\text { Agreeableness }\end{array}$} & $0.13^{* *}$ & 0.04 & 0.42 & $0.09^{* *}$ & $-0.10^{* *}$ & $0.05^{* *}$ & 0.07 & 0.46 \\
\hline & \multicolumn{3}{|l|}{ Status } & \multicolumn{5}{|c|}{ Positive \& Negative \& Status } \\
\hline & $b_{01}$ & $R_{m}$ & $R_{c}$ & $b_{01}$ & $b_{02}$ & $b_{03}$ & $R_{m}$ & $R_{c}$ \\
\hline $\begin{array}{l}\text { S1: } \\
\text { Agreeableness }\end{array}$ & - & - & - & - & - & - & - & - \\
\hline \multirow[t]{4}{*}{$\begin{array}{l}\text { S2: } \\
\text { Agreeableness }\end{array}$} & 0.00 & 0.00 & 0.36 & $0.12^{* *}$ & $-0.11^{* *}$ & -0.01 & 0.07 & 0.45 \\
\hline & \multicolumn{3}{|c|}{ Impression } & \multicolumn{5}{|c|}{ Positive \& Negative \& Impression } \\
\hline & $b_{01}$ & $R_{m}$ & $R_{c}$ & $b_{01}$ & $b_{02}$ & $b_{03}$ & $R_{m}$ & $R_{c}$ \\
\hline & $0.07 *$ & 0.01 & 0.27 & $0.19^{* *}$ & $-0.26^{* *}$ & $0.04^{*}$ & 0.19 & 0.50 \\
\hline $\begin{array}{l}\text { S2: } \\
\text { Agreeableness }\end{array}$ & $0.11^{* *}$ & 0.02 & 0.39 & $0.10^{* *}$ & $-0.11^{* *}$ & $0.07^{*}$ & 0.07 & 0.46 \\
\hline
\end{tabular}

Note. All variables were measured at the within-person level (Level 1). $\mathrm{R}_{\mathrm{m}}^{2}=$ Marginal $\mathrm{R}^{2}$ indicates the proportion of variance explained for only the fixed effects of the model; $\mathrm{R}_{\mathrm{c}}^{2}=$ Conditional $\mathrm{R}^{2}$ indicates the overall proportion of explained variance when including the random effect estimates. All coefficients are unstandardized. All predictors were person-centered prior to analysis to control for between person variance in affect. All predictors were allowed to randomly vary. Liking=liking one's interaction partners; Wanting = wanting to be in the situation one is in; Status = having low (1) vs. high (5) status relative to one's interaction partner; and Impression = caring about the impression one makes. Situational variables and affect were the IVs, personality states were the DV

$* p<0.05$.

** $p<0.01$.

Table 6

Within-person associations between situations, affective states, and openness.

\begin{tabular}{llllllllll}
\hline & \multicolumn{1}{l}{ Common } & \multicolumn{7}{c}{ PA \& NA \& Common } \\
\hline & $b_{01}$ & $R_{m}$ & $R_{c}$ & $b_{01}$ & $b_{02}$ & $b_{03}$ & $R_{m}$ & $R_{c}$ \\
\hline \multirow{2}{*}{ S1: Openness } & $-0.13^{* *}$ & 0.02 & 0.27 & $0.33^{* *}$ & $-0.07^{*}$ & $-0.15^{* *}$ & 0.15 & 0.45 \\
& Constrain & & \multicolumn{7}{c}{ Positive \& Negative \& Constrain } \\
& $b_{01}$ & $R_{m}$ & $R_{c}$ & $b_{01}$ & $b_{02}$ & $b_{03}$ & $R_{m}$ & $R_{c}$ \\
S1: Openness & $-0.08^{* *}$ & 0.01 & 0.28 & $0.34^{* *}$ & -0.05 & 0.02 & 0.12 & 0.43
\end{tabular}

Note. All variables were measured at the within-person level (Level 1).) $\mathrm{R}_{\mathrm{m}}^{2}=$ Marginal $\mathrm{R}^{2}$ indicates the proportion of variance explained for only the fixed effects of the model; $\mathrm{R}_{\mathrm{c}}{ }_{\mathrm{c}}=$ Conditional $\mathrm{R}^{2}$ indicates the overall proportion of explained variance when including the random effect estimates. All coefficients are unstandardized. All predictors were person-centered prior to analysis to control for between person variance in affect. All predictors were allowed to randomly vary. $\mathrm{PA}=$ Positive Affect NA $=$ Negative Affect; Common $=$ how common/familiar the situation is; Constrain = how much the situation constrains one's behavior. Situational variables and affect were the IVs, personality states were the DV. 
(Study 1: $\mathrm{R}_{\mathrm{c}}^{2}=0.50$; Study 2: $\mathrm{R}_{\mathrm{c}}^{2}=0.45$; see Table 2 for reference) shows that these situation variables explained very little in state agreeableness above and beyond affect (Study 1: $\leqslant 2 \%$; Study 2: $\leqslant 1 \%$ ). These results suggest that, although there may be meaningful withinperson variance in state agreeableness that is not entirely accounted for by affect, the current evidence does not provide much support for the notion that how agreeable a person is in the moment can also be predicted from relevant situation variables.

\subsubsection{Predicting fluctuations in openness}

The results in Table 6 show that people reported being more open to new experiences when they were in situations that were less common/familiar and less constraining. The association between common/ familiar and state openness remained significant after accounting for affect. The addition of common/familiar as a predictor of openness with positive and negative affect increased the amount of variance explained by $4 \%$ in Study 1 (from $R_{c}^{2}=0.41$ to $R_{c}^{2}=0.45$; see Table 2 for reference). These results show that there is a small but potentially meaningful within-person variance in state openness that is not entirely accounted for by affect.

\section{Discussion}

\subsection{Summary of results}

The results from two independent samples indicate that fluctuations in personality states may be more than fluctuations in affect for some Big Five constructs, although affect clearly plays an important role in the fluctuations in our personality states we go about our day. Overall, our results are consistent with previous research that examining the associations between affect and personality at the within- and between-person levels: extraversion and neuroticism are both strongly related to affect. However, we also found that agreeableness and openness strongly covaried with affect at the within-person level, and that affect accounted for a moderate amount of within-person variance in conscientiousness as well, though the average slope was quite small.

Our primary research question was whether fluctuations in Big Five states could be accounted for by fluctuations in affect. Across both studies, all Big Five constructs showed strong associations with affect at the within-person level (Study 1: $\mathrm{R}_{\mathrm{c}}^{2}=0.28-0.57$; Study 2: $\left.\mathrm{R}_{\mathrm{c}}^{2}=0.30-0.52\right)$. There was significant heterogeneity in slopes for all associations between the Big Five states and affect states, suggesting there may be individual differences in how (or how strongly) affect is related to fluctuations in personality states. These results suggest that the within-person variability in personality states cannot be accounted for entirely by fluctuations in affect, but we could not be sure that the remaining within-person variance in personality states was true variance (and not error variance).

To test whether there was remaining true variance in personality states after accounting for affect, we searched for situational variables that would be likely to predict fluctuations in personality states above and beyond affect. We started by examining the situation variable studying/working. We reasoned that studying/working likely impacts a broad range of college students' thoughts, feelings, and behaviors (i.e., state personality). Even after accounting for fluctuations in affect, we found that studying/working predicted fluctuations in conscientiousness and had small effects for predicting neuroticism and extraversion. We next tested situation variables that we expected to impact state agreeableness and openness but found little evidence that variance in these personality states could be predicted by situation variables even after accounting for affect. These findings suggest that within-person fluctuations for most of the Big Five are largely, but perhaps not completely, attributable to fluctuations in affect.

Notably, the marginal $\mathrm{R}^{2}$ coefficients for positive and negative affect (Study 1: $\mathrm{R}_{\mathrm{m}}^{2}=0.01-0.25$; Study $2: \mathrm{R}_{\mathrm{m}}^{2}=0.01-0.25$ ) were descriptively much smaller than the conditional $\mathrm{R}^{2}$ coefficients (Study $1: \mathrm{R}_{\mathrm{c}}^{2}=0.28-0.57$; Study $\left.2: \mathrm{R}_{\mathrm{c}}^{2}=0.30-0.52\right)$, indicating that much of the influence of affect on personality states occurs at the person-specific level. For example, conscientiousness showed only very weak fixed effects for positive and negative affect at the marginal level (Study 1: $\mathrm{R}_{\mathrm{m}}^{2}=0.01$; Study $2: \mathrm{R}_{\mathrm{m}}^{2}=0.01$ ) but strong associations at the conditional level (Study 1: $\mathrm{R}_{\mathrm{c}}{ }_{\mathrm{c}}=0.28$; Study 2: $\mathrm{R}_{\mathrm{c}}{ }_{\mathrm{c}}=0.30$ ). This indicates that only focusing on the fixed effects of affect on personality states may obscure important individual differences in how affect and conscientiousness (and other personality states) are related - some people may be more conscientious when they are feeling better (or may feel better when they are being more conscientious); while others may be more conscientious when they are feeling worse (or may feel worse when they are being more conscientious; see Fig. 1).

This pattern of results for the fixed effects of affect on the Big Five personality states is also consistent with results from similar analyses reported by Ching et al. (2014). When they included Big Five states as simultaneous predictors of positive affect, they found that extraversion, and, to a lesser extent, agreeableness, neuroticism, and openness tended to covary with positive affect. When they included Big Five states as simultaneous predictors of negative affect, they found that neuroticism, and, to a lesser extent, extraversion, agreeableness, and conscientiousness, tended to covary with negative affect. The substantial consistency across our studies is notable given that they used affect as the outcome rather than the predictor, included all five Big Five domains as simultaneous predictors, and their samples came from five cultures.

We also replicated previous research (Church et al., 2013; Fleeson, 2001; Fleeson \& Gallagher, 2009) that found a great deal of withinperson variance in Big Five personality states - as much as the withinperson variance in affect. This was true across both studies, despite different items being used to measure Big Five states in the two studies. Consistent with past research, there was more within-person variance than between-person variance for both personality traits and affect.

\subsection{Strengths and limitations}

One important strength of this research is that we were able to conduct parallel analyses in two different samples. This allows us to test the stability of our effect estimates and achieve a relatively large total sample size $(\mathrm{N}=539)$. In addition, the items used to measure state personality were different in the two studies, providing some evidence of the generalizability of the findings to various operationalizations of the core constructs. However, it is possible that two items per construct was not sufficient to capture the full content of each personality construct, making it difficult to precisely answer the question of what it means to say that personality states are "more than" positive and negative affect. In addition, one assumption of the current research is that the structure of personality at the state level mirrors the betweenperson Big Five structure, an assumption that requires further examination (Borkenau \& Ostendorf, 1998; Cervone, 2005). We hope the current studies provide a first step towards understanding the relation between personality states and affect, but more work is needed to understand the structure of state personality and validate state personality scales. 
A related limitation of our design was that positive and negative affect were only assessed with one item per construct. Future research should examine the more nuanced aspects of affect and emotions by using a broader range of items, such as varying arousal levels, in order to increase the reliability of these measures and capture the full affective circumplex (Barrett \& Russell, 1999; Larsen \& Diener, 1992). Ongoing research (e.g., Chung \& Denissen, 2016) continues to pursue the goal of constructing and validating a measure of emotions at the within-person level. Such advancements will improve our ability to understand how the specific affective and emotional components influence personality states.

Our studies used EMA to capture within-person fluctuations in personality, affect, and situations as they were happening in participants' real lives over 1-2 weeks. EMA is arguably the best available method for capturing within-person processes, especially for internal states such as affect and some personality states (e.g., neuroticism). However, our surveys were ultimately self-reports, and many of the limitations of global self-report measures apply. For example, EMA selfreports reports are susceptible to response set effects, self-deception, and self-presentation (Scollon, Kim-Prieto, \& Diener, 2009). Future research should supplement EMA with other, non-self-report methods. Specifically, the Electronically Activated Recorder (EAR; Mehl et al., 2001) provides an observer-based measure of overt behavior (e.g., talkativeness, kindness) and some features of the situation (e.g., socializing vs. working, topic of conversation, etc.). Of course, the EAR has its own set of methodological limitations, but a combination of EMA and EAR methods would allow researchers to untangle which results are specific to the self's perspective and which are robust across methods.

Both samples in the current study were drawn from the same population of college students, and, ideally, we would like to know whether these findings generalize to people of a different age, socioeconomic status, and culture (though see Ching et al., 2014, for evidence that culture may not be a strong moderator of the association between personality states and affect). In addition to ensuring generalization across populations, it is possible that assessing affect and personality states over an hour did not capture important processes that occur on the timescale of seconds or minutes. Adjusting the time scope of assessment would enhance our ability to accurately assess the relation between personality states and affect.

Lastly, the focus of the current article was on assessing the degree to which affect explained the variance in state personality, but the relation between personality states and affect is likely bi-directional. In addition, social-cognitive theory suggests that situations play an important role, triggering affective processes that mediate the influence of situations on behavioral responses (e.g., Downey \& Feldman, 1996; Downey, Freitas, Michaelis, \& Khouri, 1998; Downey, Mougios, Ayduk, London, \& Shoda, 2004). Future research using intensive longitudinal data is needed to reach firm conclusions regarding the direction and flow of these complex processes (Back \& Vazire, 2015; Vater \& Schröder-Abé, 2015; Wilson et al., 2015).

\subsection{Implications and future directions}

These results have several implications for personality theory and research. First, these results suggest that people's momentary fluctuations in personality states are mostly due to fluctuations in their positive and negative affect. There may be reliable within-person variance for some personality constructs even after accounting for affect, but affect seems to play a leading role in explaining variance in personality states. Future research should continue to search for situational variables that predict fluctuations in affect and personality states in order to examine the (likely multi-directional) causal associations between situation characteristics, affect, and personality states.

Second, our results suggest that, on average, people tend to be more extraverted, emotionally stable, open to new experiences, and (to a lesser extent) conscientious when they are feeling better (i.e., lower NA and higher PA). These associations are not entirely surprising there is a good deal of content overlap between extraversion and positive affect and between neuroticism and negative affect. However, our results suggest that state affect may also be an important component of state agreeableness and openness. The association between state openness and state positive affect is consistent with existing theories of state openness and positive affect (Fredrickson, 2001) but has not, to our knowledge, been examined before (c.f., Ching et al., 2014). Likewise, the association between state agreeableness and affect raises interesting possibilities about the underlying causes of prosocial behavior. Future research should explore the dynamic interplay between state affect and state personality. Moreover, these results suggest that researchers conducting studies on within-person personality dynamics should include measures of state affect to examine how much of their findings can be accounted for by affect.

It is also likely that other factors, besides affect and situational variables, predict fluctuations in personality states. For example, motives and roles may play a large influence in explaining why people's personality states vary from moment to moment (McCabe \& Fleeson, 2012; Wood, 2007; Wood \& Roberts, 2006). People may fluctuate in their daily desire to do well academically, and this may influence state conscientiousness. Our results suggest that exploring such explanations for fluctuations in personality states may be warranted because there is still unexplained variance in personality state fluctuations remaining after accounting for affect and situational variables.

Finally, our results, like those of other researchers examining within-person variability in personality (e.g., Sherman et al., 2015) indicate that there are substantial individual differences in the withinperson associations we examined. People have varying degrees of associations between state affect and state personality (or between situation characteristics and state personality). For example, a closer examination of our results, depicted in Fig. 1, indicate that the weak average slopes between state conscientiousness and state affect might belie important individual differences. That is, high state conscientiousness seems to be associated with high levels of positive affect for some and low levels of positive affect for others. The test of heterogeneity in slopes predicting state conscientiousness was significant for both positive affect (Study $1 \tau_{01}=0.02, p=0.004$; Study $2 \tau_{01}=0.03$, $p<0.001$ ) and negative affect (Study $1 \tau_{01}=0.01, p=0.041$; Study $2 \tau_{01}=0.03, p<0.001$ ), suggesting that future research should examine whether these individual differences in the association between conscientiousness and affect are reliable, and if so, identify moderators. Indeed, the random effects for slopes were significant in all of our models, indicating that there were individual differences in slopes across all models, though as Fig. 1 shows, except for the conscientiousness models, people's slopes tended to be in the same direction and varied mostly in degree rather than direction.

Future research should examine potential moderators of these individual differences - for whom is openness strongly associated with positive affect, and for whom is the association weaker? Individual differences in these slopes may be explained by trait personality, culture, age, well-being, and other factors that may subsequently predict important outcomes. For example, people with a strong positive association between state conscientiousness and positive affect (i.e., people who are happiest when they are being organized and responsible) 
may experience greater success in school and work or greater increases in conscientiousness, over time.

\subsection{Conclusion}

Across two studies, we found that within-person fluctuations in personality are mostly accounted for by fluctuations in affect. The associations between state personality and affect were substantial enough that personality researchers studying within-person dynamics should include measures of affect and examine whether accounting for affect alters their observed results. Of course, affect is a component of personality, so we do not advocate always removing the shared variance between state affect and state personality when studying the latter. Recognizing that part of being more agreeable (or extraverted, emotionally stable, or open) than usual is being in a good mood will help us better understand these dynamic personality processes.

In addition, there may be meaningful within-person variance in personality leftover after accounting for affect, or a mediating process where situations influence affect, which then influences personality states. This suggests that personality and social psychologists should continue our quest to identify situational triggers of personality fluctuations, and individual differences in these 'if... then' contingencies. This research will help answer some of the most fundamental questions in our field. The work presented here serves as part of the foundation necessary to explore these more complex questions.

\section{Uncited references}

Kreft, Kreft, and de Leeuw (1998) and Nezlek (2010).

\section{Appendix A. Study 1 Ecological Momentary Assessment (EMA)}

"Please take a moment and think of what you were doing from 10 to 11 am
(noon-1 pm, $2-3 \mathrm{pm}, 4-5 \mathrm{pm}, 6-7 \mathrm{pm}) . "$
In a few words, what were you doing from $8 \mathrm{pm}$ to $9 \mathrm{pm}$ ? (Open Response)
Were you interacting with other people?
$(0,1,2,3-5,3+5)$
How much did you want to be there?
Is what you were doing....(1 = Work, $5=$ Fun)
The following items were answered on a 1-5 Likert-type scale:
dependable, self- disciplined
anxious, easily upset
open to new experiences, complex
reserved, quiet
sympathetic, warm
disorganized, careless
calm, emotionally stable
conventional, uncreative
happy
extraverted, enthusiastic
critical, quarrelsome
depressed, blue
lonely
How much positive emotion did you experience
How much negative emotion did you experience
How high was your self-esteem
How biased was your perception of yourself
How stressful was the situation?
How common/familiar was the situation?
How much did the situation constrain your behavior?
How much did you want to be there?
"Please refer to the people you interacted with for the following questions:"
How well do you know them?
How much do you like them?

How much did you care about how you came across to them? How superficial (i.e. shallow) to substantive (i.e., deep) were the conversations?

\section{Appendix B. Study 2 Ecological Momentary Assessment (EMA)}

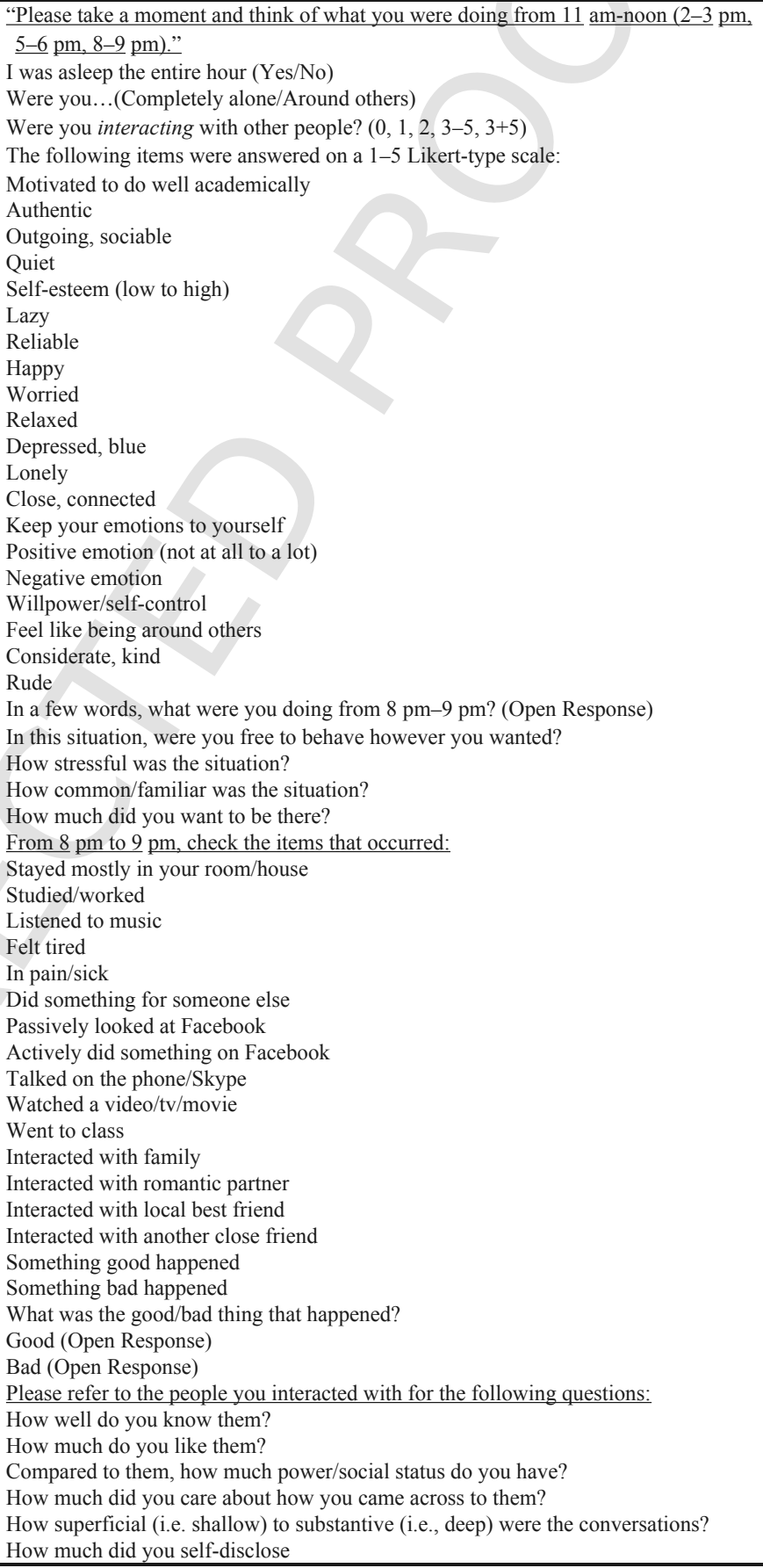

\section{References}

Allport, G.W., 1937. Personality. Holt, New York, 173-181.

Ashton, M.C., Lee, K., Goldberg, L.R., 2007. The IPIP-HEXACO scales: An alternative, public-domain measure of the personality constructs in the HEXACO model. Personality and Individual Differences 42, 1515-1526. 
Back, M.D., Vazire, S., 2015. The social consequences of personality: Six suggestions for future research. European Journal of Personality 29, 296-307.

Barrett, L.F., Barrett, D.J., 2001. An introduction to computerized experience sampling in psychology. Social Science Computer Review 19, 175-185.

Barrett, L.F., Russell, J.A., 1999. The structure of current affect: Controversies and emerging consensus. Current Directions in Psychological Science 8, 10-14.

Bates, D., Maechler, M., Bolker, B., \& Walker, S. (2014). lme4: Linear mixed-effects models using Eigen and S4. R package version 1.1-7. This is computer program ( $\mathrm{R}$ package). The URL of the package is: <http://CRAN.R-project.org/ package $=1 \mathrm{me} 4>$

Bollich, K.L., Rogers, K.H., Vazire, S., 2015. Knowing more than we can tell people are aware of their biased self-perceptions. Personality and Social Psychology Bulletin http://dx.doi.org/10.1177/0146167215583993.

Borkenau, P., Ostendorf, F., 1998. The Big Five as states: How useful is the five-factor model to describe intraindividual variations over time? Journal of Research in Personality $32,202-221$.

Cattell, R.B., 1943. The description of personality: Basic traits resolved into clusters. The Journal of Abnormal and Social Psychology 38, 476-506.

Cattell, R.B., 1944. Psychological measurement: Normative, ipsative, interactive. Psychological Review 51, 292-303.

Cervone, D., 2005. Personality architecture: Within-person structures and processes. Annual Review of Psychology 56, 423-452.

Charles, S.T., Reynolds, C.A., Gatz, M., 2001. Age-related differences and change in positive and negative affect over 23 years. Journal of Personality and Social Psychology 80, 136-151.

Ching, C.M., Church, A.T., Katigbak, M.S., Reyes, J.A.S., Tanaka-Matsumi, J., Takaoka, S., ... Ortiz, F.A., 2014. The manifestation of traits in everyday behavior and affect: A five-culture study. Journal of Research in Personality 48, 1-16.

Chung, J. M., \& Denissen, J. J. A. (2016, April). Development of a measure of emotional life. Oral presentation to be at the biannual meeting for the World Association for Personality Psychology, Buzios, Brazil.

Church, A.T., Katigbak, M.S., Ching, C.M., Zhang, H., Shen, J., Mazuera Arias, R., ... Alvarez, J.M., 2013. Within-individual variability in self-concepts and personality states: Applying density distribution and situation/behavior approaches across cultures. Journal of Research in Personality 47, 922-935.

Costa, P.T., McCrae, R.R., 1980. Influence of extraversion and neuroticism on subjective well-being: Happy and unhappy people. Journal of personality and social psychology 38, , 668-678.

Costa, P.T., McCrae, R.R., 1980. Somatic complaints in males as a function of age and neuroticism: A longitudinal analysis. Journal of Behavioral Medicine 3, ,245-257.

Costa, P.T., McCrae, R.R., 1992. Four ways five factors are basic. Personality and Individual Differences 13, 653-665.

Csikszentmihalyi, M., Larson, R., 1987. Validity and reliability of the experience-sampling method. The Journal of Nervous and Mental Disease 175, 526-536.

David, J.P., Green, P.J., Martin, R., Suls, J., 1997. Differential roles of neuroticism, extraversion, and event desirability for mood in daily life: An integrative model of top-down and bottom-up influences. Journal of Personality and Social Psychology $73,149-159$.

DeNeve, K.M., Cooper, H., 1998. The happy personality: A meta-analysis of 137 personality traits and subjective well-being. Psychological Bulletin 124, 197-229.

Diener, E., Lucas, R.E., 1999. 11 personality and subjective well-being. Well-being: Foundations of Hedonic Psychology 213-229.

Diener, E., Oishi, S., Lucas, R.E., 2003. Personality, culture, and subjective well-being: Emotional and cognitive evaluations of life. Annual Review of Psychology $54,403-425$.

Diener, E., Suh, E.M., Lucas, R.E., Smith, H.L., 1999. Subjective well-being: Three decades of progress. Psychological Bulletin 125, 276-302.

Downey, G., Feldman, S.I., 1996. Implications of rejection sensitivity for intimate relationships. Journal of Personality and Social Psychology 70, 1327-1343.

Downey, G., Freitas, A.L., Michaelis, B., Khouri, H., 1998. The self-fulfilling prophecy in close relationships: Rejection sensitivity and rejection by romantic partners. Journal of Personality and Social Psychology 75, 545-560.

Downey, G., Mougios, V., Ayduk, O., London, B.E., Shoda, Y., 2004. Rejection sensitivity and the defensive motivational system: Insights from the startle response to rejection cues. Psychological Science 15, 668-673.

Fleeson, W., 2001. Toward a structure-and process-integrated view of personality: Traits as density distributions of states. Journal of Personality and Social Psychology $80,1011-1027$.

Fleeson, W., 2007. Situation-based contingencies underlying trait-content manifestation in behavior. Journal of Personality 75, 825-862.

Fleeson, W., Gallagher, P., 2009. The implications of Big Five standing for the distribution of trait manifestation in behavior: Fifteen experience-sampling studies and a meta-analysis. Journal of Personality and Social Psychology 97, 1097-1114.

Fleeson, W., Jayawickreme, E., 2015. Whole trait theory. Journal of Research in Personality 56, 82-92.

Fleeson, W., Malanos, A.B., Achille, N.M., 2002. An intraindividual process approach to the relationship between extraversion and positive affect: Is acting extraverted as "good" as being extraverted?. Journal of Personality and Social Psychology $83,1409-1422$.
Fossum, T.A., Barrett, L.F., 2000. Distinguishing evaluation from description in the personality-emotion relationship. Personality and Social Psychology Bulletin 26, 669-678.

Fournier, M.A., Moskowitz, D.S., Zuroff, D.C., 2008. Integrating dispositions, signatures, and the interpersonal domain. Journal of Personality and Social Psychology $94,531-545$.

Fredrickson, B.L., 2001. The role of positive emotions in positive psychology: The broaden-and-build theory of positive emotions. American Psychologist 56, 218-226.

Goldberg, L.R, 1981. Language and individual differences: The search for universals in personality lexicons. In: In: Wheeler, L. (Ed.), Review of Personality and Social Psychology, Vol. 2. Sage, CA, pp. 141-165

Goldberg, L.R., 1990. An alternative "description of personality": The Big-Five factor structure. Journal of Personality and Social Psychology 59, 1216-1229.

Goldberg, L.R., 1992. The development of markers of the Big-Five factor structure. Psychological Assessment 4, 26-42.

Gosling, S.D., Rentfrow, P.J., Swann, W.B., 2003. A very brief measure of the BigFive personality domains. Journal of Research in Personality 37, 504-528.

Gross, J.J., Sutton, S.K., Ketelaar, T., 1998. Affective-reactivity views. Personality and Social Psychology Bulletin 24, 279-288.

Hektner, J.M., Schmidt, J.A., Csikszentmihalyi, M., 2007. Experience-sampling methods: Measuring the quality of everyday life. Sage, Thousand Oaks, CA.

Heller, D., Komar, J., Lee, W.B., 2007. The dynamics of personality states, goals, and well-being. Personality and Social Psychology Bulletin 33, 898-910.

Hofmann, W., Baumeister, R.F., Förster, G., Vohs, K.D., 2012. Everyday temptations: An experience sampling study of desire, conflict, and self-control. Journal of Personality and Social Psychology 102, 1318-1335.

Hox, J., 2010. Multilevel analysis: Techniques and applications. Routledge.

Izard, C.E., Libero, D.Z., Putnam, P., Haynes, O.M., 1993. Stability of emotion experiences and their relations to traits of personality. Journal of Personality and Social Psychology 64, 847-860.

John, O.P., Naumann, L.P., Soto, C.J., 2008. Paradigm shift to the integrative Big Five trait taxonomy: History, measurement, and conceptual issues. In: John, O.P.,

Robins, R.W., Pervin, L.A. (Eds.), Handbook of personality: Theory and research. Guilford Press, New York, pp. 114-158.

John, O.P., Srivastava, S., 1999. The Big Five trait taxonomy: History, measurement, and theoretical perspectives. In: Pervin, L.A., John, O.P. (Eds.), Handbook of personality: Theory and research, 2nd ed. Guilford, New York, pp. 102-138.

Kreft, I.G, Kreft, I., de Leeuw, J., 1998. Introducing multilevel modeling. Sage.

Krull, J.L., MacKinnon, D.P., 2001. Multilevel modeling of individual and group level mediated effects. Multivariate Behavioral Research 36, 249-277.

Larsen, R.J., Diener, E., 1992. Promises and problems with the circumplex model of emotion. In: In: Clark, M.S. (Ed.), Emotion: The Review of Personality and Social Psychology, Vol. 13. Sage, Thousand Oaks, CA, pp. 25-59.

Larsen, R.J., Ketelaar, T., 1989. Extraversion, neuroticism, and susceptibility to positive and negative mood induction procedures. Personality and Individual Differences $10,1221-1228$.

Larsen, R.J., Ketelaar, T., 1991. Personality and susceptibility to positive and negative emotional states. Journal of Personality and Social Psychology 61, 132-140.

Lewin, K., 1936. Principles of topological psychology. McGraw-Hill, New York.

Lucas, R.E., Fujita, F., 2000. Factors influencing the relation between extraversion and pleasant affect. Journal of Personality and Social Psychology 79, 1039-1056.

Magnusson, D., Endler, N.S. (Eds.), 1977. Personality at the crossroads: Current issues in interactional psychology. Lawrence Erlbaum, pp. 3-31.

McAdams, D.P., 1994. A psychology of the stranger. Psychological Inquiry $5,145-148$.

McCabe, K.O., Fleeson, W., 2012. What is extraversion for? Integrating trait and motivational perspectives and identifying the purpose of extraversion. Psychological Science 23, 1498-1505

McNiel, J.M., Fleeson, W., 2006. The causal effects of extraversion on positive affect and neuroticism on negative affect: Manipulating state extraversion and state neuroticism in an experimental approach. Journal of Research in Personality $40,529-550$

McNiel, J.M., Lowman, J.C., Fleeson, W., 2010. The effect of state extraversion on four types of affect. European Journal of Personality 24, 18-35.

Mehl, M.R., Conner, T.S. (Eds.), 2011. Handbook of research methods for studying daily life. Guilford Press, London, England.

Mehl, M.R., Pennebaker, J.W., Crow, D.M., Dabbs, J., Price, J.H., 2001. The electronically activated recorder (EAR): A device for sampling naturalistic daily activities and conversations. Behavior Research Methods, Instruments, \& Computers 33, 517-523.

Meyer, G.J., Shack, J.R., 1989. Structural convergence of mood and personality: Evidence for old and new directions. Journal of Personality and Social Psychology 57, 691-706.

Mischel, W., Shoda, Y., 1995. A cognitive-affective system theory of personality: Reconceptualizing situations, dispositions, dynamics, and invariance in personality structure. Psychological Review 102, 246-268. 
Nezlek, J.B., 2010. Multilevel modeling and cross-cultural research. In: Matsumoto, D., van de Vijver, A.J.R. (Eds.), Cross-cultural research methods in psychology. Oxford University Press, Oxford, pp. 299-347.

Nezlek, J.B., 2012. Diary methods for social and personality psychology. In: Nezlek, J.B. (Ed.), The SAGE library in social and personality psychology methods. Sage Publications, London.

Nezlek, J.B., Plesko, R.M., 2001. Day-to-day relationships among self-concept clarity, self-esteem, daily events, and mood. Personality and Social Psychology Bulletin 27, 201-211.

Pytlik Zillig, L.M., Hemenover, S.H., Dienstbier, R.A., 2002. What do we assess when we assess a big 5 trait? A content analysis of the affective, behavioral and cognitive processes represented in the big 5 personality inventories. Personality and Social Psychology Bulletin 28, 847-858.

Rusting, C.L., 1999. Interactive effects of personality and mood on emotion-congruent memory and judgment. Journal of Personality and Social Psychology $77,1073-1086$

Schutte, N.S., Malouff, J.M., Segrera, E., Wolf, A., Rodgers, L., 2003. States reflecting the Big Five dimensions. Personality and Individual Differences 34, 591-603.

Scollon, C.N., Kim-Prieto, C., Diener, E., 2009. Experience sampling: Promises and pitfalls, strengths and weaknesses. Journal of Happiness Studies 4, 5-34.

Sherman, R.A., Rauthmann, J.F., Brown, N.A., Serfass, D.G., Jones, A.B., 2015. The independent effects of personality and situations on real-time expressions of behavior and emotion. Journal of Personality and Social Psychology 109, 872-888.

Simmons, J.P., Nelson, L.D., Simonsohn, U., 2012. A 21 Word Solution. Dialogue: The Official Newsletter of the Society for Personality and Social Psychology $26(2), 4-7$.

Slatcher, R.B., Vazire, S., 2009. Effects of global and contextualized personality on relationship satisfaction. Journal of Research in Personality 43, 624-633.

Snijders, T.A.B., Bosker, R.J., 1999. Multilevel analysis: An introduction to basic and advanced multilevel modeling. Sage Publications, Thousand Oaks.

Solomon, B.C., Vazire, S., 2014. You are so beautiful... to me: Seeing beyond biases and achieving accuracy in romantic relationships. Journal of Personality and Social Psychology 107, 516-528.
Spain, J.S., Eaton, L.G., Funder, D.C., 2000. Perspectives on personality: The relative accuracy of self versus others for the prediction of emotion and behavior. Journal of Personality 68, 837-867.

Suh, E., Diener, E., Fujita, F., 1996. Events and subjective well-being: Only recent events matter. Journal of Personality and Social Psychology 70, 1091-1102.

Thalmayer, A.G., Saucier, G., Eigenhuis, A., 2011. Comparative validity of brief to medium-length Big Five and Big Six Personality Questionnaires. Psychological Assessment 23, 995-1009.

Vater, A., Schröder-Abé, M., 2015. Explaining the link between personality and relationship satisfaction: Emotion regulation and interpersonal behaviour in conflict discussions. European Journal of Personality 29, 201-215.

Vazire, S., Wilson, R.E., Solomon, B., Bollich, K., Harris, K., Weston, S., ... Jackson, J.J., 2015. Personality and Interpersonal Roles (PAIRS). Study in Progress

Watson, D., Clark, L.A., 1992. Affects separable and inseparable: On the hierarchical arrangement of the negative affects. Journal of Personality and Social Psychology 62, 489-505.

Westfall, J., Yarkoni, T., 2016. Statistically controlling for confounding constructs is harder than you think. PLoS ONE 11, e0152719.

Wilson, K., Gullone, E., 1999. The relationship between personality and affect over the lifespan. Personality and Individual Differences 27, 1141-1156.

Wilson, R.E., Harris, K., Vazire, S., 2015. Personality and friendship satisfaction in daily life: Do everyday social interactions account for individual differences in friendship satisfaction?. European Journal of Personality 29, 173-186.

Wilson, R., Vazire, S., 2015. Taking personality to the next level: what does it mean to know a person?. Emerging trends in the social and behavioral sciences: an interdisciplinary, searchable, and linkable resource,

Wood, D., 2007. Using the PRISM to compare the explanatory value of general and role-contextualized trait ratings. Journal of Personality 75, 1103-1126.

Wood, D., Roberts, B.W., 2006. Cross-sectional and longitudinal tests of the personality and role identity structural model (PRISM). Journal of Personality 74, 779-810. 